\title{
Strategies to promote adherence to nutritional advice in patients with chronic kidney disease: a narrative review and commentary
}

This article was published in the following Dove Press journal: International Journal of Nephrology and Renovascular Disease 2 February 2016

Number of times this article has been viewed

Judith A Beto

Katherine A Schury

Vinod K Bansal

Division of Nephrology and Hypertension, Loyola University Healthcare System, Loyola University of Chicago, Maywood, IL, USA
Correspondence: Judith A Beto Division of Nephrology and Hypertension, Loyola University Healthcare System, Loyola University of Chicago, 2160 South First Avenue, Maywood, IL 60I53, USA

Tel +l 7082270126

Email jbeto@luc.edu
Abstract: Chronic kidney disease (CKD) requires extensive changes to food and lifestyle. Poor adherence to diet, medications, and treatments has been estimated to vary between $20 \%$ and $70 \%$, which in turn can contribute to increased mortality and morbidity. Delivering effective nutritional advice in patients with CKD coordinates multiple diet components including calories, protein, sodium, potassium, calcium, phosphorus, and fluid. Dietary intake studies have shown difficulty in adhering to the scope and complexity of the CKD diet parameters. No single educational or clinical strategy has been shown to be consistently effective across CKD populations. Highest adherence has been observed when both diet and education efforts are individualized to each patient and adapted over time to changing lifestyle and CKD variables. This narrative review and commentary summarizes nutrition education literature and published strategies for providing nutritional advice in CKD. A cohort of practical and effective strategies for increasing dietary adherence to nutritional advice are provided that include communicating with "talking control" principles, integrating patient-owned technology, acknowledging the typical food pattern may be snacking rather than formal meals, focusing on a single goal rather than multiple goals, creating active learning and coping strategies (frozen sandwiches, visual hands-on activities, planting herb gardens), and involving the total patient food environment.

Keywords: talking control, technology-enhanced learning, hemodialysis, nutrition education, education strategies

\section{Introduction}

Decades of large observational research cohorts such as the Nurses' Health Study and the Framingham Heart Study have linked epidemiological diet patterns to selected health outcomes. Yet, a recent editorial documented that in the last 35 years there has been little significant shift in consumer-driven changes of adherence to governmentrecommended dietary guidelines promoting health in adults. ${ }^{1}$ Clearly, consumers will continue to select foods that they want to eat. Chronic kidney disease (CKD) patients are not different.

All chronic diseases require adaptations to lifestyle. There is an impressive body of peer-reviewed literature and consumer-based education programs documenting that human behavior changes are needed to achieve health goals. However, even the singular concept of calorie control to achieve or maintain a healthy body weight has not been attained in the general population. The success rate to reduce obesity continues to be low and is seldom sustainable even when only controlling calories. ${ }^{2}$

In chronic diseases, there is often disconnection between goals of the health care team and the patient. The goals that people set for themselves have to be considered. 
One cannot define a concept of well-being or better health that ignores what the patient wants even if they have not formally created a measurable "goal". Adaptation to a new situation, whether good or bad, consists in a large part of thinking less and less about it. ${ }^{3}$ Awareness may naturally decrease as a patient becomes more and more familiar with CKD. Poor adherence to diet, medications, and treatment has been reported in different CKD studies to vary between $20 \%$ and $70 \%$ depending on the assessment method (objective versus self-reported). ${ }^{4}$ Higher mortality and morbidity have been reported in patients, who do not meet "goals" defined by the health care team.,

Extensive changes to food and lifestyle are required in CKD on a continual basis. Many diet components must be monitored such as calories, protein, sodium, potassium, calcium, phosphorus, and fluid. Dietary intake studies have shown difficulty in adhering to the scope and complexity of the CKD diet parameters. No single educational or clinical strategy has been shown to be consistently effective across CKD populations. Highest adherence has been observed when both diet and education efforts are individualized to each patient and adapted over time to changing lifestyle and CKD variables. ${ }^{7}$ Taste and convenience appear to be the driving factors in food selection. The education focus may be more effective by addressing one opportunity at a time, rather than a broad long-term diet planning strategy. ${ }^{1}$

This narrative review and commentary summarizes nutrition education literature and published strategies for providing effective nutritional advice in CKD. A cohort of practical and effective strategies for increasing dietary adherence are provided that include communicating with "talking control" principles, integrating patient-owned technology, acknowledging the typical food pattern may be snacking rather than formal meals, focusing on a single goal rather than multiple goals at once, creating active learning and coping strategies (frozen sandwiches, visual hands-on activities, planting herb gardens), and involving the total patient food environment.

\section{Nutrient requirements in CKD}

A long list of diet components must be monitored and coordinated in CKD. These typically include calories, protein (type as well as amount), sodium, potassium, calcium, phosphorus, and fluid (in food as well as in liquids). In diabetics, carbohydrate monitoring will be added to this list. In children, growth parameters become an added focus. ${ }^{7-11}$

Another layer of individualization is required for stage of kidney failure, degree of progression, type of renal replacement treatment, and presence of residual kidney function. Patients need additional adaptation for comorbidi- ties, nutritional status (over nutrition through malnutrition), single/multiple nutrient imbalance, and drug-nutrient interactions. Additional considerations need to be made for food intake preferences (ie, cultural, religious, and personal) and lifestyle factors (ie, financial, food availability, food preparation facilities, physical ability and cooking skills, and transportation to obtain food). ${ }^{11}$ Finally, CKD is seldom static-every component is potentially in motion with changing order and priority.

\section{Nutritional requirements in CKD}

Nutritional advice in CKD is based on nutrient requirements linked to published evidence and clinical guidelines. ${ }^{7-20}$ There are multiple recognized sources for nutrition requirements. Many of the original metabolic studies comprise the historical data that have not been clinically studied in contemporary global patient populations. The initial evidence-based guidelines have not been updated for more than a decade. ${ }^{8}$ Table 1 provides a general overview of dietary parameters in CKD. Compliance to nutrition requirements can be measured indirectly using data such as laboratory values, body weight, and/or self-reported dietary intake records. ${ }^{7,11,21}$

\section{Assessment of nutritional advice content}

Assessing and individualizing nutrient requirements in $\mathrm{CKD}$ should be a coordinated health care team effort. In US CKD centers delivering maintenance peritoneal dialysis or hemodialysis, the nutrition component of patient care is required to be delivered by a dietitian with special expertise and experience in renal nutrition. The Center for Medicare Services (CMS) in the US has established minimal education requirements of the registered dietitian nutritionist credential with 1 year of clinical experience to deliver nutrition education to patients covered by CMS-paid renal replacement therapies. ${ }^{22}$ Standards of practice and standards of professional performance for registered dietitians (generalist, specialty, and advanced) in the care of chronic kidney patients are updated regularly. ${ }^{23}$ An advanced renal specialist credential is available after passing a certification examination from the Commission on Dietetic Registration.

In other countries, nutritional advice is often delivered by a more varied group of professionals that include dietitians and nutritionists. Dietary adherence is central to the management of CKD when renal replacement therapy is not available and/ or progression to end-stage kidney failure is a key goal.

\section{Dietary intake studies in CKD}

Adherence can be measured using a comparison between prescribed and actual food intake. Dietary intake in CKD 
Table I Summary of selected nutrition requirements for adults with varying stages of chronic kidney disease (CKD) as recommended by published guidelines

\begin{tabular}{|c|c|c|c|}
\hline Nutrient & $\begin{array}{l}\text { CKD stages 3-5 without maintenance } \\
\text { dialysis (GFR categories } 3-5 \text { ) }\end{array}$ & $\begin{array}{l}\text { CKD stage } 5 \text { with maintenance dialysis } \\
\text { (kidney failure) }\end{array}$ & $\begin{array}{l}\text { Post-transplant (guided by CKD } \\
\text { stage/category of kidney function) }\end{array}$ \\
\hline Protein $^{\mathrm{a}}$ & $\begin{array}{l}0.6-0.8 \mathrm{~g} / \mathrm{kg} / \text { day of } \mathrm{BW} \text { with at least } 50 \% \\
\text { HBV to potentially slow disease progression } \\
\text { (particularly in diabetics) and achieve/maintain } \\
\text { adequate serum albumin OR } 0.3 \mathrm{~g} / \mathrm{kg} / \text { day } \\
\text { of BW supplemented with keto acids }\end{array}$ & $\begin{array}{l}\text { I.I-I.5 g/kg/day of BW (HD) with at least } \\
50 \% \mathrm{HBV} \text { to achieve/maintain adequate serum } \\
\text { albumin levels in conjunction with sufficient } \\
\text { protein-sparing caloric intake }\end{array}$ & $\begin{array}{l}0.8-1.0 \mathrm{~g} / \mathrm{kg} / \text { day of } \mathrm{BW} \text { with } 50 \% \\
\text { coming from HBV }\end{array}$ \\
\hline Energy & $\begin{array}{l}25-35 \mathrm{kcal} / \mathrm{kg} / \text { day of } \mathrm{BW} \text { to achieve or } \\
\text { maintain goal body weight }\end{array}$ & $\begin{array}{l}25-35 \mathrm{kcal} / \mathrm{kg} / \text { day of } \mathrm{BW} \text { to achieve or } \\
\text { maintain goal body weight; include estimated } \\
\text { caloric absorption from PD fluid as applicable }\end{array}$ & $\begin{array}{l}25-35 \mathrm{kcal} / \mathrm{kg} / \text { day of BW to achieve } \\
\text { or maintain goal body weight }\end{array}$ \\
\hline Fat & $\begin{array}{l}\text { General population recommendation of } \\
<30 \% \text { of total calories from fat; emphasis } \\
\text { on healthy fat sources }\end{array}$ & $\begin{array}{l}\text { Focus on type of fat and carbohydrate to } \\
\text { manage dyslipidemia; pattern unique in CKD }\end{array}$ & $\begin{array}{l}\text { Focus on type of fat and carbohydrate } \\
\text { to reduce cardiovascular risk } \\
\text { or manage immunosuppressant } \\
\text { medication adverse effect } \\
\text { (dyslipidemia, glucose intolerance) }\end{array}$ \\
\hline Saturated fat & $\begin{array}{l}\text { Same as for general population; } \\
<7 \% \text { of total fat }\end{array}$ & $\begin{array}{l}\text { Reduce and substitute saturated fat sources } \\
\text { with healthier fat sources }\end{array}$ & $\begin{array}{l}\text { Reduce and substitute saturated fat } \\
\text { sources with healthier fat sources }\end{array}$ \\
\hline Sodium & $\begin{array}{l}\text { General population recommendation of } \\
\leq 2.3 \mathrm{~g} / \text { day; individualize in conjunction } \\
\text { with fluid }\end{array}$ & $\begin{array}{l}2.0-3.0 \mathrm{~g} / \text { day }(\mathrm{HD}) \text { to control interdialytic } \\
\text { fluid gain; } 2.0-4.0 \mathrm{~g} / \text { day }(\mathrm{PD}) \text { to control } \\
\text { hydration status }\end{array}$ & $\begin{array}{l}\text { General population recommendation } \\
\text { of } \leq 2.3 \mathrm{~g} / \text { day }\end{array}$ \\
\hline Potassium & $\begin{array}{l}\text { Typically not restricted until hyperkalemia is } \\
\text { present, then individualized }\end{array}$ & $\begin{array}{l}2.0-4.0 \mathrm{~g} / \text { day or } 40 \mathrm{mg} / \mathrm{kg} / \text { day of } \mathrm{BW} \text { in } \mathrm{HD} \\
\text { or individualized in PD to achieve normal } \\
\text { serum levels }\end{array}$ & $\begin{array}{l}\text { Not restricted unless hyperkalemia is } \\
\text { present, then individualized }\end{array}$ \\
\hline Calcium & Not restricted & $\begin{array}{l}2 \mathrm{~g} \text { elemental/day from dietary and medication } \\
\text { sources }\end{array}$ & Individualized to kidney function \\
\hline Phosphorus & $\begin{array}{l}\text { Typically not restricted until } \\
\text { hyperphosphatemia is present, then } \\
\text { individualized to maintain normal serum } \\
\text { levels by diet and/or phosphate binders }\end{array}$ & $\begin{array}{l}800-1,000 \mathrm{mg} / \text { day to achieve goal serum level } \\
\text { of } 3.5-5.5 \mathrm{mg} / \mathrm{dL} \text { or below; coordinate with } \\
\text { oral phosphate binder prescription }\end{array}$ & $\begin{array}{l}\text { Individualized to stage of kidney } \\
\text { function }\end{array}$ \\
\hline Fiber & Same as general population; $25-35$ g/day & Same as general population; $25-35$ g/day & $\begin{array}{l}\text { Same as general population; } \\
25-35 \mathrm{~g} / \text { day }\end{array}$ \\
\hline Fluid & $\begin{array}{l}\text { Typically not restricted unless clinically } \\
\text { indicated }\end{array}$ & $\begin{array}{l}\text { I,000 mL/day (+ urine output if present) in } \\
\mathrm{HD} \text {; greater in PD individualized to fluid status }\end{array}$ & $\begin{array}{l}\text { No restriction; matched to urine } \\
\text { output if appropriate }\end{array}$ \\
\hline
\end{tabular}

Note: aSee special considerations for vegetarians. ${ }^{16}$ Reprinted from Beto JA, Ramirez WE, Bansal VK. Medical nutrition therapy in adults with chronic kidney disease: integrating evidence and consensus into practice for the generalist registered dietitian nutritionist. J Acad Nutr Diet. 2014;1 I4(7): 1077-1087.7 Copyright @ 20I4, with permission from Elsevier.

Abbreviations: BW, body weight; GFR, glomerular filtration rate; HBV, high biological value; HD, hemodialysis; PD, peritoneal dialysis.

has been collected using food frequency questionnaires, food diaries, food records, and diet recalls. Some dietary assessment tools have been customized to the specific kidney populations and validated in individual studies.

The Modification of Diet in Renal Disease Study was the first controlled randomized dietary intake clinical trial to be conducted in CKD patients prior to onset of renal replacement therapy. ${ }^{24}$ A recent review of 29 published dietary intake studies in maintenance dialysis patients demonstrated wide variation in attaining nutrient requirement recommendations. The majority of patients were unable to meet recommended daily dietary protein and/or energy intake levels. ${ }^{25}$

A randomized prospective observational cohort of 264 adult American women undergoing maintenance peritoneal dialysis or hemodialysis in 1998-1999 used the same food frequency questionnaire as the Women's Health Initiative Study conducted in postmenopausal healthy women. Low-fat food behaviors, although not a parameter of the renal diet prescription, were reported by $30 \%-50 \%$ women undergoing maintenance dialysis. These behaviors included removing visible fat, purchasing low-fat options, and reducing the amount or type of fat when cooking. ${ }^{26}$ This finding was an interesting adaptation of the public health message to lower dietary fat in the general population. It could be postulated that meal planning for others was of greater influence than the renal diet prescription alone in this study population. It also could be inferred that American women on maintenance dialysis were more likely to purchase and prepare foods for their household.

In summary, dietary intake studies in CKD confirm challenges of both meeting nutrient recommendations and adapting dietary components to daily food intake. In particular, 
poor food choices may contribute to protein-energy wasting and accompanying higher risks for malnutrition. Food choices appear to be driven by factors other than following the complex components of the "ideal" CKD diet.

\section{Delivering nutrition advice in CKD}

Nutrition advice in CKD is most effective when matched to the specific needs and interests of patients. Individualization and one-on-one face-to-face communication are the cornerstone of achieving higher adherence. The message must be relevant and timely. The format must be interesting and have practical application in the patient's life. ${ }^{21}$ This section will highlight selected topics that have been studied in the CKD population.

\section{Nutrition labeling challenges in CKD}

Nutrition labeling was designed to be a simple education tool to provide facts to consumers. In theory, one could quickly compare commercial food products with one another as well as select products with target nutrient content. In reality, nutrition labels have been difficult for many consumers to use as intended and may lack important information. In the US, the key nutrients of phosphorus and potassium monitored in the renal diet are not mandated on the label. Globally, food labeling is variable and often voluntary.

Food prepared at home does not have nutrient data. Some restaurants are providing limited calorie content nutrient information for selected menu items, but not for other nutrients. Published recipes in magazines and cookbooks also lack consistent information.

Patients struggle how to select foods that fit into their renal diet prescription. They will gravitate toward choosing foods that are familiar and available to them. ${ }^{1}$ Adapting current recipes and food practices will often be more successful than creating new less familiar food dishes. Another effective strategy would be to reduce portion sizes of current recipes rather than dramatically change their ingredients.

Food store tours can be organized to read labels and evaluate options..$^{27}$ Food packages can be shared and used to discuss what information is missing. Additional nutrient information not found on the food label may be available on the manufacturer website or by contact through consumer information portals. Home recipes can be analyzed to give guidance to portion sizes and preparation methods. Most importantly, all of this communication needs to extend to the primary food purchasers and preparers (often not the patient).

\section{Emphasis on serum albumin and dietary protein quality}

Hypoalbuminemia has been linked to higher risk of mortality and morbidity. Dietary protein requirements in CKD are calculated to maintain lean body mass, positive nitrogen balance, and normal serum albumin. ${ }^{8-11}$

Patients with early stages of CKD are often given complicated nutritional advice to decrease the quantity of protein while increasing the high biological quality of the protein. This strategy is based on the literature showing potential slowing down of CKD progression by controlling uremic waste products. ${ }^{24}$ Numerous studies have been conducted using very low protein diets $(0.3 \mathrm{~g} / \mathrm{kg})$ in conjunction with keto acid supplements. Although very restrictive, they have been shown to potentially delay the need for renal replacement therapy in some patients. In many developing countries, the use of vegetarian diets along with keto acids has been shown to delay progression as well..$^{28-33}$

The switch to emphasizing higher protein $(\geq 1.0 \mathrm{~g} / \mathrm{kg} /$ day $)$ intake starts when the patient is in kidney failure and undergoing maintenance dialysis therapy. ${ }^{34}$ Protein-energy wasting and chronic inflammation associated with malnutrition are often associated with hypoalbuminemia. ${ }^{35}$ Peritoneal protein losses will be increased during periods of peritonitis.

Patients often exhibit taste fatigue and complain protein foods are less palatable to eat than prior to CKD. Many are unable or unwilling to ingest adequate protein. In order for protein to be used to maintain body tissue, sufficient calories need to be consumed. Actual body composition is intertwined with fluid retention making body weight a complicated measure of protein or calorie adequacy. Obese patients may be protein deficient. ${ }^{36}$

High biological protein sources include eggs, dairy products, seafood, and animal meat. Vegetarian diets require special dietary protein strategies. ${ }^{16}$ Patients with difficulty chewing and poor dental health often exhibit lower protein intake. ${ }^{37,38}$ Snack foods may contain less protein than a balanced meal. Some dialysis facilities routinely offer commercial protein supplements to be consumed during treatment to maintain serum albumin.

\section{Sodium intake and fluid retention}

Dietary sodium restriction may be more familiar than other nutrients due to public health campaigns and recognition by salty taste. In CKD, sodium intake is directly correlated to interdialytic weight gain in maintenance dialysis patients. Fluid retention over time in any stage of CKD increases the risk for comorbidities such as uncontrolled hypertension, left ventricular hypertrophy, pulmonary edema, and vascular disease. ${ }^{39}$ 
Both the American Heart Association and the National Blood Pressure Education program recommend daily sodium intake not to exceed approximately $2,300 \mathrm{mg}$ or one teaspoon salt for the general population. ${ }^{18,19}$ The Dietary Approaches to Stop Hypertension diet from the National Heart, Lung, and Blood Institute also included a $1,500 \mathrm{mg} /$ day level..$^{20}$

Patients are counseled to eliminate table salt in cooking. With less patients cooking at home, the impact of this advice is decreased. Most patients can more effectively eliminate adding salt to food when served. Commercial salt substitutes are too high in potassium to be used in CKD, but some low-sodium commercial seasonings are appropriate. Many patients complain about the loss and changes of food taste in uremia. Many cultural food seasonings and sauces (sriracha, soy sauce, and fish sauce) contain high levels of sodium but might be used creatively in small quantities to add back taste particularly in cooked proteins.

Processed foods typically contain higher sodium content than raw or home prepared alternatives. ${ }^{40,41}$ Many common foods contain more than $100 \mathrm{mg}$ sodium in a typical serving such as one slice of bread, a handful of regular crackers or nuts, a bowl of processed breakfast cereals, or a single portion of a frozen entree. Fast food meal combinations such as a sandwich with snack chips often contain more than $1,000 \mathrm{mg}$ of sodium.

Several qualitative studies have been conducted in CKD to identify key adherence barriers to sodium. Recurrent themes in a Dutch study highlighted difficulty in self-regulating intake and recognizing hidden sodium in processed foods. Participants felt their CKD lacked social support by family and friends. ${ }^{41}$ Another qualitative study of 122 maintenance hemodialysis patients found that younger patients were more reluctant to change their diet, had a higher median sodium intake, and higher average interdialytic weight gain. ${ }^{42}$

\section{Phosphorus binders and food absorption differences}

Patients with CKD often exhibit hyperphosphatemia from a combination of dietary intake and bone resorption. Lack of phosphate control has been linked to higher mortality and morbidity in the CKD population. An analysis of 22,989 maintenance hemodialysis patients (12 countries, 938 facilities) participating in the prospective randomized Dialysis Outcome Practice and Patterns Study from 1996 to 2008 reported the highest levels of nutrition status and survival were associated with better control of serum phosphorus and higher use of phosphate binders. The researchers concluded that greater adherence to phosphate binders may lead to a more liberalized diet and better nutrition..$^{43}$

Nutrition advice is centered on balancing the phosphate content of the diet with the ingestion of oral phosphate binders. The majority of the binders were studied using the traditional three meals per day model. Many dialysis patients in the US eat more small frequent meals and snacks, which may decrease the effectiveness of the binders. It has also been estimated that adherence to binder use as prescribed may be less than $50 \%{ }^{44}{ }^{49}$

Recent research has shown that phosphorus absorption varies among foods. Current nutrition advice in phosphate control is moving toward a greater understanding by both patients and health care teams on newly understood mechanisms of phosphate content and absorption. In a recent study, two different standardized diets (1,900-2,000 calories, $15 \%$ protein, $55 \%-60 \%$ carbohydrate, $25 \%-30 \%$ fat, 900 mg phosphorus) were designed using computer software: a low-additive diet made up of fresh and minimally processed foods and an additive-enhanced diet using processed options. Menus were averaged for 4 days and compared. The additive-enhanced diet contained less calcium and potassium per $100 \mathrm{~g}$ of food but the phosphorus and sodium content was $30 \%-40 \%$ higher. The investigators estimated the additive-enhanced meal pattern would require between 5 and 23 additional tablets of phosphate binders (depending on the formula/brand) to handle the larger phosphate load..$^{40}$ Current nutrition analysis software may not represent true inorganic phosphate content from additives. This information is lacking on food labels.

Phosphate absorption differences have also been studied between animal and vegetable protein. Processed meat products often contain "phosphate salts" to enhance their shelf life and taste. Many plant-based proteins have been shown to have a lower rate of phosphorus uptake than meat-based protein. This ratio concept ( $\mathrm{mg}$ of phosphorus to $\mathrm{g}$ of protein integrated with digestion absorption factor) can be essential when working with vegetarian patients who also need to maintain serum protein levels. ${ }^{9,50} \mathrm{~A}$ visual education system, a phosphorus pyramid, has been developed..$^{51}$ Examples of some phosphate absorption ratios are shown in Table 2.

\section{Diet compliance differences by demographics}

Women compared with men have reported more problems managing their renal diet. The researchers postulated that this observation may be due to greater responsibilities purchasing and preparing food that could be affected by fatigue and physical 
Table 2 Selected examples of average ratio of phosphorus to protein comparing plant and animal-based foods illustrating differences in phosphorus uptake in chronic kidney disease (CKD)

\begin{tabular}{|c|c|c|c|c|c|}
\hline Protein category & Amount & $\begin{array}{l}\text { Phosphorus } \\
\text { (mg) }\end{array}$ & $\begin{array}{l}\text { Protein } \\
\text { (g) }\end{array}$ & $\begin{array}{l}\text { Ratio of mg phosphorus } \\
\text { to } g \text { of protein }\end{array}$ & $\begin{array}{l}\text { Adjusted ratio for phosphorus } \\
\text { digestion and absorption }\end{array}$ \\
\hline \multicolumn{6}{|l|}{ Animal based } \\
\hline Chicken thigh & $3 \mathrm{oz}(120 \mathrm{~g})$ & 148 & 22.0 & 6.7 & 4.9 \\
\hline Egg, raw & I large (50 g) & 86 & 6.0 & 14.3 & 10.5 \\
\hline $\begin{array}{l}\text { Macaroni and cheese, } \\
\text { boxed, prepared }\end{array}$ & I cup $(240 \mathrm{~g})$ & 265 & 11.0 & 24.1 & 16.1 \\
\hline Milk, whole & I cup $(240 \mathrm{~mL})$ & 227 & 8.0 & 28.4 & 20.9 \\
\hline \multicolumn{6}{|l|}{ Plant-based } \\
\hline Almonds & I oz (30 g) & 139 & 6.0 & 23.2 & 13.6 \\
\hline Peanut butter, chunky & 2 Tablesp (32 g) & 101 & 8.0 & 12.6 & 7.4 \\
\hline Sunflower seeds & I oz (30 g) & 322 & 8.0 & 53.7 & 31.6 \\
\hline Tofu, firm & 3 oz (100 g) & 76 & 6.0 & 12.7 & 7.5 \\
\hline
\end{tabular}

Notes: From National Kidney Foundation ${ }^{9}$ and Garneata and Mircescu. ${ }^{28}$ Phosphate-additive amount highly variable; higher in processed foods versus natural. Ratio is mathematically calculated using the protein digestibility-corrected amino-acid score (PDCAA) and estimated phosphorus bioavailability.

health. ${ }^{49}$ Older patients have been consistently observed to be more willing to adhere to dietary parameters. ${ }^{21,44}$

Reading level and health literacy have also been studied and shown to be factors in dietary adherence. ${ }^{52}$ Aligning educational resources to cultural beliefs may also improve adherence by providing more practical applications and examples that are personalized. ${ }^{53-56}$

\section{Potassium taste and cooking method confusion}

Potassium cannot be "tasted" in foods and is seldom listed on a food label. High serum levels (hyperkalemia) may affect cardiac rhythm. Most CKD patients are unaware of their serum potassium level except once a month when a laboratory value is reported (which represents intake within the last 24 hours, not longitudinally). Patients are typically given a "high" potassium list of foods to avoid. Many of these foods can be easily avoided (banana, orange, tomato, and prune) but what foods are left to actually eat is confusing. Most fruits and vegetables contain potassium so integrating fiber into the CKD diet is limited by portion sizes and frequency of consumption. Individualized education is needed to help balance portions of commonly available foods. ${ }^{7,45}$ Special attention needs to be given to cultural foods since the potassium content may be hard to determine.

Historically, patients have been instructed on a timeintensive method to reduce the potassium content of potatoes: peel, cut in small pieces, and soak in water overnight to leach potassium. Newer methodology has documented that soaking is no longer required. Similar results can be achieved by just boiling peeled potatoes cut in small pieces in a large amount of water. Root vegetables have been documented to leach potassium in a similar manner. ${ }^{57,58}$
In summary, nutrition advice needs to be engaging and individualized. A review of qualitative studies in chronic illness using thematic analysis summarized that patients expected their health care team to provide strong relational support by finding answers for them contrasted with selfmanagement. ${ }^{54}$ In a cross-sectional qualitative survey study of hemodialysis patients in the US, better adherence was seen when team members focused on understanding individual health beliefs rather than just on disease and diet messages. ${ }^{4}$

\section{Education strategies in CKD}

Webb and Byrd-Bredbenner have shared their philosophy on overcoming consumer inertia to dietary guidance by assuring nutrition education messages have four essential components: realistic, positive, easy to understand, and actionable. They also comment that for all of this to be effective assumes that consumers will not give up eating the foods they love. ${ }^{1}$ Focusing on choice of foods rather than elimination of foods creates a positive message. In this section, creative education strategies to promote adherence in the CKD population and in our own clinical experience will be discussed.

\section{Communicate using "talking control" principles}

Talking control is a cognitive behavior technique that was first studied in depressed older non-CKD patients..$^{59}$ It can be described a creating a "befriending" relationship. Others have compared it with an "oral facebook" technique. All the information that is shared is controlled by both the patient and the provider. The key components of talking control as we have used it in our CKD population are 1) focusing on a general conversation without the specific intent of education 
change, 2) listening more than talking, and 3) limiting the "talk" to 5-10 minutes.

We initially conducted a talking control exercise in 50 random patients undergoing maintenance hemodialysis (38\% of our unit) over 12 weeks. A team of 26 interdisciplinary health care team members including 18 students met with assigned patients 5-10 minutes a week. After introducing themselves, they opened their communication with a non-dialysis topic (weather, traffic) and let the conversation continued by listening to the patient. At the end of the 5-10 minutes, they quickly ended the conversation and thanked the patient for visiting with them. At the end of the 12 weeks, $82 \%$ of the patients had met or exceeded mean target laboratory goals (albumin, phosphorus) compared with $66 \%$ pre-exercise. The blinded full unit scheduled annual patient satisfaction survey response was higher in "feeling of belonging" and "staff involvement in care". ${ }^{60}$

Since then, talking control has been implemented in many units throughout the US. A renal network in the Midwest used it as a qualitative communication goal and found an overall increase in both patient and staff satisfaction. ${ }^{61}$ All staff should be invited to be involved, including support staff (janitors, front desk) as they are part of who the patient "sees" as contributing to their care. Our experience has been that all patients are approached. Those that refuse initially often ask to be included later - as they observe the brief encounters with others as something they being eliminated from and the experience looks interesting. The cost of training is minimal as most patient and staff are already familiar with the "facebook" concept. The key component of talking control is maintaining restricted contact time within a single visit. This appears to drive increased expectations of contact by the patient rather than promote boredom of repeated information.

\section{Accept the fact that patients often do not eat three traditional meals a day}

Recent consumer studies in the US have confirmed that $50 \%$ of calories are consumed within "snacks" rather than meals. ${ }^{44,48,49}$ Dietary intake patterns in our own unit have confirmed this strong trend. Phosphate binder medication, traditionally prescribed to be taken "with meals" now should be directed to times of higher food intake. The mechanism of phosphate binding assumes that the phosphate binder is in the gut in proximity to the food. Individual binders may vary in their mechanism. Therefore, patients who are taking binders may be missing the impact if not matched to food pattern. $^{62}$
It is also important to recognize the food environment of "others" that impact food choices. If a patient lives alone, then they may be in complete control of food choices. However, most patients live with others. Nutrition advice is of little or no value if delivered to the patient when they are not the food "gatekeepers". ${ }^{21}$ Our personal single-center observational experience has confirmed the majority of written handouts we send home with the patient do not reach the intended audience. The bag many patients bring to dialysis may contain an archival collection of handouts that never are looked at again. Connecting with the "others" is an important determinant of adherence. We have had some success in meeting family members at a Sunday dialysis open house. A shelf inventory survey or a cell phone picture of the contents of the home refrigerator may provide snapshot data of food available in the home. The use of "Skype" as a face-to-face communication method has been studied in non-CKD populations. ${ }^{63}$ Multiple creative ways of outreach are required with no single method known to be more effective than another.

\section{Take advantage of the amazing technology they own \\ Technology can be integrated into the nutritional advice cycle of CKD}

The majority of our patients have amazing technology at their fingertips in their "smart" cell phones and tablets. Our experience supports patients may not have a car or an adequate budget for food but they have a phone that is never turned off and is always with them. As with most consumers, they are proud to show and tell us about their technology. They bring them faithfully without reminders to every dialysis session! The technology is under their control and meets the Health Information Patient Protection Act (HIPPA) guidelines in the US: what they collect, how they collect, and what they share stays on their own phones and in their own possession.

Audio alerts and other notifications can be programmed into most cell phones. Health care team members can use a variety of methods (stationery, prescription pad, unit brochure, and business card) to "prescribe" cell phones reminder rings for medication and dialysis sessions. In our experience, patients willingly bring them to their cell phone provider for help and have consistently received high quality technology assistance to program their phones by support staff. Many have received "free" songs, downloads of unique alerts, and learned how to implement future changes themselves.

Applications or "apps" are available for many CKD parameters. There are several renal diet apps. Some of our 
patients use support apps meant for weight loss. Some have the ability to scan items at the grocery store. The nutritional label appears on their phone screen, which can be used for conversations during dialysis sessions. The content and ability of these "apps" change frequently. ${ }^{64}$

Lifestyle records can be recorded easily on cell phones. Patients are asked to take a picture every time they eat, for example, or every time they take a medication over 24 hours or between dialysis sessions. Each picture has a time and date automatically recorded by the device, which makes recall easy. Diet intakes are greatly enhanced because foods can be seen and discussed. Interactive nutrition sessions become less tedious and more realistic. Valuable information is now visual: size of plate, method of food preparation, setting where meal was consumed, and who prepared the meal. All of this information might have been lost using the format of a traditional dietary intake assessment. Patients feel a sense of connection and individualization when you use a picture they have taken to problem-solve together a challenge. One patient decided to take their morning medication when they took the dog out, since the first and last picture on his lifestyle record was that activity. Another, after reviewing a day's worth of activities, found that they ate a total of 18 separate times in a single day, which visually documented times that could be correlated to medication timing reminders or opportunities for more renal friendly preplanned snacks.

\section{Focus on one treatment parameter goal and others will follow}

The complexities of the renal diet prescription are overwhelming, even for the most dedicated patient. The foods that are present in the home for the rest of the occupants seldom meet the renal diet prescription. Like all of us, food choices are in constant motion. Seasonal foods change, food cost drives what foods are actually purchased, and availability of food may be restricted by transportation or skills needed. Foods obtained from a food pantry seldom align with renal parameters: dried beans and legumes, high salt processed canned entrees and soups, packaged mixes such as pancake and macaroni/cheese choices, canned meats.

Research has supported that focusing on one goal may make the quest easier. In controlling one diet parameter, others usually follow along. For example, emphasis on phosphorus adherence will increase awareness and promote changes in other diet parameters since all foods are interrelated in nutrients. Focusing on parathyroid hormone control may bring serum phosphorus in alignment by reducing bone reabsorption. ${ }^{13}$ Attention to albumin may promote better appetite and lean body weight. Working with a patient to select a goal of interest to them may enhance collaborative learning.

Focusing on a single goal also makes "success" more attainable. A sense of trust is promoted between patient and provider in a single message/goal as a team. A single problem focus promotes multiple solutions. Patients feel that they are making progress rather than being reminded of lack of progress. Patients often add other goals in small steps, which over time promote greater adherence since it was self-initiated.

Finally, focusing on one goal may promote more honesty in solving underlying problems. ${ }^{21,65}$ We have found that patients become more comfortable sharing their struggles in this way which may help the health care team identify barriers to treatment. One of our patients felt she was on a "quiz show" whenever we sat with her and tried to re-align goals. Now, with a single goal, she stated she feels like a participant on a "reality series" and enjoys sharing problems because they are discussed without judgment. Her goal has become more connected to her own personal outcome which was never really defined. Rather than looking from treatment to treatment, she is defining progress over a longer period of time. When goals are examined over 6-12 months, they may have more value. Translating progress using visual pie charts and bar graphs may have more meaning. ${ }^{52,55}$

Nutrition goals can also be linked to life goals. For example, higher fluid or phosphorus awareness often translates to better medication adherence. This in turn promotes better health to live to see a grandchild grow up or wait longer on the kidney transplant registry. One patient had a relative come forward to be worked up as a potential kidney donor when they saw marked changes in overall attitude and health.

\section{Think outside of the box - make routine advice fun and creative}

Our signature snack in our unit is the frozen sandwich. Table 3 illustrates some of the snacks we use to keep our patients interested in nutritional content and more importantly may be consumed by other members of their family. Our patients tell us that nothing is worse than feeling sorry for yourself while everyone around you eats your favorite foods. So we have worked to make creative exciting foods available to our patients at low cost that they can share with others - and make others want to eat their foods too.

Moderation and creativity are part of the challenge of a chronic diet. Often our patients do not have the energy 
Table 3 Nutrient content of selected frozen sandwiches and snacks that are appropriate for chronic kidney disease (CKD) patients to use when taking oral medications requiring food or as caloric snack from Loyola University Healthcare Dialysis

\begin{tabular}{|c|c|c|c|c|c|c|c|}
\hline Item & Kcal & Protein (g) & Fiber (g) & Fat (g) & Sodium (mg) & Phosphorus (mg) & Potassium (mg) \\
\hline \multicolumn{8}{|l|}{ One whole Sandwich } \\
\hline Peanut butter smooth with grape jelly & 375 & 14.4 & 5.5 & 16 & 394 & 214 & 323 \\
\hline Peanut butter crunchy with grape jelly & 376 & I3.1 & 6.0 & 16 & 402 & 203 & 350 \\
\hline Peanut butter (Simply Jiff ${ }^{\mathrm{TM}}$ ) Brand with jelly & 388 & 14.0 & 5.6 & 15 & 321 & 203 & 350 \\
\hline Unsalted butter and jelly & 290 & 7.0 & 3.8 & $\mathrm{II}$ & 265 & 116 & 142 \\
\hline \multicolumn{8}{|l|}{ Other snack } \\
\hline Ten unsalted almonds (0.5 oz) & 84 & 3.0 & 1.5 & 7 & 0 & 66 & 100 \\
\hline Ten gumdrops & 142 & 0 & 0 & 0 & 15 & I & 20 \\
\hline
\end{tabular}

Notes: Estimated nutritional analysis using Foodworks ${ }^{\circledR}$ (The Nutrition Company, Long Valley NJ, USA, version 13.0.I); variations should be calculated by renal dietitian. Patients are encouraged to take a phosphate binder with their snacks as appropriate. Frozen peanut butter/jelly sandwich (Yield: 10 sandwiches). Take one loaf of white or whole wheat bread (generic). Lay out 20 slices of bread (typically one loaf) in two rows. Spread one jar ( $10-12$ ounces/300-360 g) peanut butter on top row of 10 slices. Spread one jar ( 10 ounces/300 g) grape jelly on bottom row of 10 slices. Cut each sandwich into quarters, freeze in plastic bags or plastic wrap. Eat frozen in portions or as full sandwich (making ahead is a key to have readily available). Selected patient-created variations: I. Unsalted butter and jelly (Spread room temperature butter/4 ounces [ $120 \mathrm{~g}]$ per 10 slices of bread). 2. Unsalted butter and drizzled honey or maple syrup or flavored pancake syrup. 3. Unsalted butter and fresh herbs: fresh basil, fresh dill, fresh parsley. 4. Unsalted butter and dried spices: cinnamon and sugar, lemon peel, orange peel, paprika. 5. Unsalted butter and raw vegetables: shredded carrot, green onion, jalapeno pepper slices. 6. Marshmallow fluff and graham cracker crumbs (pediatric CKD). 7. Condensed milk (thin film) and unsalted butter. 8. Nutella ${ }^{\mathrm{TM}}$ (thin film) and unsalted butter.

to make food when they are hungry so instead they grab "what is available". They may not have the cooking skills to prepare food at home. We found the frozen sandwich is the perfect option. They can make a whole loaf of sandwiches at one time and freeze them, to be eaten when needed. From the original butter sandwich, our patients have created more than 40 varieties at a lower cost than any purchased option. The highest complaint we hear is that their families are eating their sandwiches - and they happily make more of their signature "dish".

Having a fast, easy, and inexpensive prepared snack available has also helped with taking medication consistently. Many of our patients are prescribed cinacalcet, a calcimimetic agent, which is recommended to be taken with food. It is also a coated pill so it is important to eat a sufficient amount of food to move the medication from the mouth, through the stomach, and into the upper small intestine where it was studied as most bioavailable. If taken without food, coated pills often dissolve and become "uncoated" in the wrong place. This may contribute to gastrointestinal symptoms. Timing of this medication and other "coated" pills is necessary to achieve accurate serum values.

Creative education strategies promote adherence by making a "required" activity more interesting and fun. Linking a medication to a consistent time each day is easier to remember if you can match it to a chronic habit observed in the lifestyle record. ${ }^{62}$ Several of our patients connect timing to a favorite daily television show or align it with a daily activity such as walking the dog or babysitting the grandkids after school. Adding a reminder by cell phone ring/alert uses existing technology that the patient is already familiar using. Creating a preprepared snack such as a frozen sandwich assures food is readily available to take with the medication - and can be eaten by others as well promoting a sense of "community" to promote adherence.

Another example of a dietary challenge was consuming commercial soups during the cold Chicago winter. Canned soups are high in fluid and sodium. Low-sodium commercial options were more than double the cost of regular soups. Also low-sodium soups were not found in many small neighborhood grocery stores. They were heavy to carry home on the bus from the store. Most patients did not prepare their own soups. As a result of this challenge, our patients helped us create a cohort of "personalized" low-sodium single serving soups in a beverage cup using jarred baby food as a base. Commercial baby food in the US does not have added sodium or phosphorus additives. Potassium, sodium, and phosphorus are found on the nutrition label. It can be purchased in convenience food marts, neighborhood stores, discount stores, and traditional stores. The cost of a jar of baby food is reasonable (around \$0.30 US currency).

Table 4 shares some soup recipes based on one jar of baby food (approximately 2.5 ounces/75 g) and one "jar-full" of other liquid along with creative options. One microwavesafe beverage cup (6-8 ounces, 180-240 mL), a spoon, and a microwave are needed. To start the project, patients could choose one flavor of baby food from a list - and when they had returned a recipe they created, they could select another jar of baby food to try. Some patients now bring their baby food to a restaurant and ask for hot water in a coffee cup to create their own first course. Others have expanded to "summer soups" that are cold. Another group is now using this concept to make one-serving entrees and desserts. The possibilities are endless. We have our own food creative group evolving 
Table 4 Nutrient content of selected low-sodium single-serving soup recipes developed by chronic kidney disease (CKD) patients using baby food as a primary ingredient from the "Soup It Up" education program at Loyola University Healthcare Dialysis

\begin{tabular}{llllllll}
\hline Item & Serving & Kcal & Protein $(\mathrm{g})$ & Fat $\mathbf{( g )}$ & Sodium $(\mathbf{m g})$ & Phosphorus (mg) & Potassium (mg) \\
\hline Cream soup & One & 123 & 10.0 & 6.0 & 143 & 100 & 224
\end{tabular}

Notes: Estimated nutritional analysis using Foodworks ${ }^{\circledR}$ version I3.0.I (The Nutrition Company, Long Valley, NJ, USA); variations should be calculated by a renal dietitian. Patients are encouraged to take a phosphate binder as appropriate. See Supplementary Material for Basic Recipe.

with little effort. The fun and excitement sustains itself. When a recipe is brought in, the dietitians use a computer software program to create a nutrition label/content. We have successfully involved dietetic students from a local university to help with the analysis. If a recipe ingredient is of concern, then problem-solving is used to investigate options.

We also use this concept to support family recipes. We have asked patients to share family recipes or recipes that they make at home frequently. We use a computer software program to analyze their nutrition content. We re-type the recipe along with the "portion" size that makes the most sense. One year, we published a holiday recipe book with patient shared recipes. Stories can be added to personalize them. This way a patient can still eat a traditional or cultural food but be more informed about the content. As one patient stated, "I am not going to stop eating this dish during the holidays but now I hopefully won't be in the hospital either with fluid overload again". We also work with them to substitute ingredients that may make the recipe more renal friendly without dramatically changing the content. This strategy works with traditional foods. Several of our patients consume traditional foods when their relatives visit. One patient successfully navigates increased consumption of cultural foods his mother brings each year. We strive to include the patient in the health care team so we can collectively work together to safely incorporate these foods in their diets by portion control and avoid unintended consequences such as hospital visits for hyperkalemia or fluid overload.

All of this "awareness" has driven our unit to create an herb garden in pots outside our unit. Fresh herbs are usually too expensive for patients to purchase in stores. They are full of flavor and easy low-sodium alternatives to incorporate in their meals. It is a signature ingredient in many of our frozen sandwiches. We provide plastic bags and scissors along with recipes near the pots. We are proud to share that this concept has been replicated in units throughout the country. We can confidently say we have a garden movement going! Many units have replaced flowers with herbs. Others, like us, move the herbs inside during the winter months. Some units have patients "tending" while they wait for their transportation. Some units have involved the entire health care team and patients in building planter boxes. Others provide small pots of herbs for patients to plant in their own gardens through local food cooperative gardens. Another unit features a monthly "herb" tasting in the waiting room using smear of unsalted butter combined with chopped herbs on an unsalted cracker. The scope of this simple concept is endless. It embodies the true sense of interactive "show and tell" nutrition advice.

\section{Conclusion}

This narrative review and commentary has summarized the nutrition education literature and published strategies for providing nutritional advice in CKD. The goal of effective nutritional advice should emphasize positive actions rather than guilt or blame. A cohort of practical and effective strategies for increasing dietary adherence were discussed. These included integrating patient-owned technology, acknowledging the typical food pattern may be snacking rather than formal meals, focusing on a single goal rather than multiple goals, creating active learning, and coping strategies (frozen sandwiches, customized soups, and visual hands-on activities) that involve the total patient food environment. Many strategies shared are from our own personal experience within our single dialysis unit. The majority of these individualized practices are observational. The application to other CKD populations is not studied and may be limited.

The strongest determinants of food choices remain convenience and taste. Interactive nutrition advice can promote adherence in medication and treatment parameters concurrently. The communication technique of "talking control" has been demonstrated to be effective in maintenance hemodialysis populations to engage them in constructive conversations that promote adherence. Creative action rather than passive learning has been shown to patients into engage problem-solving and self-management.

The most important message in adherence is individualization. There is no single education or nutrition advice strategy that has been shown to work in the majority of patients. Each patient is their own challenge. It is up to the health care team to keep the communication consistent but creative and evolving. Adherence is a true measure of patient engagement. 


\section{Disclosure}

The authors report no conflicts of interest in this work.

\section{References}

1. Webb D, Byrd-Bredbenner C. Overcoming consumer inertia to dietary guidance. Adv Nutr. 2015;6(4):391-396.

2. Jensen MD, Ryan DH, Apovian CM, et al. AHA/ADD/TOS guideline for the management of overweight and obesity in adults: a report of the American College of Cardiology/American Heart Association Task Force on Practice Guidelines and The Obesity Society. Circulation. 2013;129(25 Suppl 2):S102-S138.

3. Kahneman D. Thinking, Fast and Slow. London, UK: Penguin Books, 2011.

4. Karamanidou C, Clatworthy J, Weinman J, Horne R. A systematic review of the prevalence and determinants of nonadherence to phosphate binding medication in patients with end-stage renal disease. BMC Nephrol. 2008;9:2.

5. Hsu KL, Fink JC, Ginsberg JS, et al. Self-reported medication adherence and adverse patient safety events in CKD. Am J Kidney Dis. 2015;66(4):621-629.

6. Ibrahim S, Hossam M, Belal D. Study of non-compliance among chronic hemodialysis patients and its impact on patients' outcomes. Saudi J Kidney Dis Transpl. 2015;26(2):243-249.

7. Beto JA, Ramirez WE, Bansal VK. Medical nutrition therapy in adults with chronic kidney disease: integrating evidence and consensus into practice for the generalist registered dietitian nutritionist. J Acad Nutr Diet. 2014;114(7):1077-1087.

8. National Kidney Foundation. KDOQI clinical practice guidelines for nutrition in chronic renal failure. Am J Kidney Dis. 2001;37(1 Suppl 2): S66-S70.

9. National Kidney Foundation. KDOQI clinical practice guideline for nutrition in children with CKD: 2008 update. AmJKidney Dis. 2009;53(Suppl2): S1-S124.

10. National Kidney Foundation Council on Renal Nutrition. Pocket Guide to Nutrition Assessment of the Patient with Kidney Disease. 5th ed. McCann L, editor. New York: National Kidney Foundation, 2015.

11. Renal Dietitians Dietetic Practice Group of the Academy of Nutrition and Dietetics and the Council on Renal Nutrition of the National Kidney Foundation. A Clinical Guide to Nutrition Care in Kidney Disease. 2nd ed. Byham-Gray L, Stover J, Wiesen K, editors. Chicago: Academy of Nutrition and Dietetics, 2013.

12. Academy of Nutrition and Dietetics Evidence Analysis Library [homepage on the Internet]. Chronic kidney disease. Evidence-based nutrition practice guideline. June 2010. Available from: http://andevidencelibrary.com/topic. cfm?cat=3927. Published June 2010. Accessed June 15, 2015.

13. National Kidney Foundation [homepage on the Internet]. Kidney Disease Outcomes Quality Initiative clinical practice guidelines for bone and mineral management. Available from: http://www.kidney.org/ professionals/kdoqiguidelines.updates. Accessed June 15, 2015.

14. National Kidney Foundation [homepage on the Internet]. Kidney Disease Outcomes Quality Initiative clinical practice guidelines for management of dyslipidemia for patients with kidney disease. Available from: http://www.kidney.org/professionals/kdoqiguidelines.updates. Accessed June 15, 2015.

15. National Kidney Foundation [homepage on the Internet]. Kidney Disease Outcomes Quality Initiative clinical practice guidelines for diabetes and chronic kidney disease. Available from: http://www. kidney.org/professionals/kdoqiguidelines.updates. Accessed June $15,2015$.

16. Pagenkemper J. Vegetarian diets in chronic kidney disease. Ren Nutr Forum. 2012;16(3):21-23.

17. Institute of Medicine of the National Academies [homepage on the Internet]. Report on sodium intake in populations: assessment of evidence. Available from: http://www.iom.med/Reports/2013/Sodium-intake-inpopulations-assessment-of-evidence.aspx. Accessed June 15, 2015.
18. American Heart Association [homepage on the Internet]. Diet and lifestyle guidelines. Available from: http://my.americanheart.org/ professional/StatementsGuidelines/ByTopic. Accessed June 15, 2015.

19. Kalogeropoulos AP, Georgiopoulou W, Murphy RA, et al. Dietary sodium content, mortality, and risk for cardiovascular events in older adults. The Health, Aging, and Body Composition (Health ABC) Study. JAMA Intern Med. 2015;175(3):410-419.

20. National Heart, Lung, and Blood Institute. Your Guide to Lowering Your Blood Pressure with DASH. US Department of Health and Human Services, National Institutes of Health, NIH Publication No 06-4082, Revised April 2006.

21. Holli BB, Beto JA. Nutrition Counseling and Education Skills for Dietetics Professionals. 6th ed. Philadelphia: Wolters Kluwer/Lippincott Williams \& Wilkins, 2014.

22. Department of Health and Human Services. Centers for Medicare and Medicaid Services. 42 CFR Parts 405, 410, 413, et al. Medicare and Medicaid Programs: Conditions for Coverage for End-Stage Renal Disease Facilities: Final Rule, Federal Register, April 15, 2008.

23. Kent PS, McCarthy MP, Burrowes JD, et al. Academy of Nutrition and Dietetics and National Kidney Foundation: revised 2014 standards of practice and standards of professional performance for registered dietitian nutritionists (competent, proficient, and expert) in nephrology nutrition. J Acad Nutr Diet. 2014;114(9):1448-1457. e45.

24. Piccoli GB, Vigotti FN, Leone F, et al. Low-protein diets in CKD: How can we achieve them? A narrative, pragmatic review. Clin Kidney J. 2015;8:61-70.

25. Therrien M, Byham-Gray L, Beto J. A review of dietary intake studies in maintenance dialysis patients. $J$ Ren Nutr. 2015;25(4):329-338.

26. Luttrell KJ, Beto JA, Tangney CC, for the National Kidney Foundation Council on Renal Nutrition Second National Research Question Collaborative Study Group. Selected nutrition practices of women on hemodialysis and peritoneal dialysis: observations from the NKF-CRN Second National Research Question Collaborative Study. J Ren Nutr. 2014;24(2):81-91.

27. Hill LJ. Chronic kidney disease supermarket tours: An intervention to promote healthful food choices. Ren Nutr Forum. 2014;33(3):7-9.

28. Garneata L, Mircescu G. Effect of low protein diet supplemented with keto acids on progression of kidney disease. J Ren Nutr. 2013;23(3): 210-213.

29. Piccoli GB, Deagostini MC, Vigotti FN, et al. Which low-protein diet for which CKD patient? An observational, personalized approach. Nutrition. 2014;30(9):992-999.

30. Bellizzi V, Chiodini P, Cupisti A, et al. Very low-protein plus ketoacids in chronic kidney disease and risk of death during end-stage renal disease: a historical cohort controlled study. Nephrol Dial Transplant. 2015;30(1):71-77.

31. Aparicio M, Bellizzi V, Chauveau P, et al. Do ketoanalogues still have a role in delaying dialysis initiation in CKD predialysis patients? Nephrol Dial Transplant. 2013;28(9):2295-2305.

32. Piccoli GB, Ferraresi M, Deagostini MC, et al. Vegetarian low-protein diets supplemented with keto analogues: a niche for the few or an option for many? Nephrol Dial Transplant. 2013;28(9):2295-2305.

33. Shah AP, Kalantar-Zadeh K, Kopple JD. Is there a role for ketoacid supplements in the management of CKD? Am J Kidney Dis. 2015;65(5): 659-673.

34. Kistler BM, Fitsche PJ, Ikizler TA, Wilund KR. Rethinking the restriction of nutrition during hemodialysis therapy. J Ren Nutr. 2015;25(2): $81-87$.

35. Ekramzadeh M, Mazloom Z, Jafari P, Ayatollahi M, Sagheb MM. Major barriers responsible for malnutrition in hemodialysis patients: challenges to optimal nutrition. Nephrourol Mon. 2014;6(6):e23158.

36. Ricardo AC, Athavale A, Chen J, et al. Periodontal disease, chronic kidney disease and mortality: results from the third national health and nutrition examination survey. BMC Nephrol. 2015;16:97.

37. Yuvaraj A, Vijayan M, Alex M, Abraham G, Nair S. Effect of highprotein supplementation therapy on subjective global assessment of CKD-5D patients. Hemodial Int. Epub 2015 Jun 24. 
38. Beto J, Jelebinkov M, Trepashko E, Kaneva K. Scannicchio L, Bansal V. Correlations between serum albumin and number of intact teeth in relation to selected biomarkers (IF-G, FGF-23, PTH) in a chronic hemodialysis randomized cohort. Poster presented at: The American Society of Nephrology; November; 2012; San Diego, CA.

39. John A, Alpert PT, Kawi J, Tandy R. The relationship between selfefficacy and fluid and dietary compliance in hemodialysis patients. Clin Scholar Rev. 2013;6(2):98-104.

40. Carrigan A, Klinger A, Choquette SS, et al. Contribution of food additives to sodium and phosphorus content of diets rich in processed foods. J Ren Nutr. 2014;24(1):13-19.

41. Clark-Cutaia MN, Ren D, Hoffman LA, Burke LE, Sevick MA. Adherence to hemodialysis dietary sodium recommendations: influence of patient characteristics, self-efficacy, and perceived barriers. J Ren Nutr. 2014;24(2):92-99.

42. Meuleman Y, Ten Brinke L, Kwakernaak AJ, et al. Perceived barriers and support strategies for reducing sodium intake in patients with chronic kidney disease: a qualitative study. Int J Behav Med. 2015;22(4): 530-539.

43. Lopes AA, Tong L, Thumma J, et al. Phosphate binder use and mortality among hemodialysis patients in the DOPPS: evaluation of possible confounding by nutritional status. Am J Kidney Dis. 2012;60(1):90-101.

44. Chater AM, Parham R, Rilery S, Hutchison AJ, Horne R. Profiling patient attitudes to phosphate binding medication: a route to personalising treatment and adherence support. Psychol Health. 2014;29(12): 1407-1420.

45. Elliott JO, Ortman C, Almaani S, Lee YH, Jordon K. Understanding the associations between modifying factors, individual health beliefs, and hemodialysis patients' adherence to a low-phosphorus diet. J Ren Nutr. 2015;25(2):111-120.

46. Karrero JJ, Cozzolino M. Nutritional therapy, phosphate control, and renal protection. Nephron Clin Pract. 2014;126:1-7.

47. Shi Y, Zhao Y, Liu J, Hou Y, Zhao Y. Educational intervention for metabolic bone disease in patients with chronic kidney disease: a systematic review and meta-analysis. J Ren Nutr. 2014;24(6):371-384.

48. Walker R. Practical solutions to improve adherence to phosphate binders. J Ren Nurs. 2014;6(4):174-176.

49. Therrien M, Byham-Gray L, Denmark R, Beto J. Comparison of dietary intake among women on maintenance dialysis to a Women's Health Initiative cohort: results from the NKF-CRN Second National Research Question Collaborative Study. J Ren Nutr. 2014;24(2):72-80.

50. Cupisti A, Kalandar-Zadeh K. Management of natural and added dietary phosphorus burden in kidney disease. Semin Nephrol. 2013;33(2):180-190.

51. DiAlessandro C, Piccoli GB, Cupisti A. The "phosphorus pyramid": a visual tool for dietary phosphorus management in dialysis and CKD patients. BMC Nephrol. 2015;16:9.
52. Morony S, Flynn M, McCaffery KJ, Jansen J, Webster AC. Readability of written materials for CKD patients: a systematic review. Am J Kidney Dis. 2015;65(6):842-850.

53. Senteio C, Veinot T. Trying to make things right: adherence work in high-poverty, African American neighborhoods. Qual Health Res. 2014;24(12):1745-1756.

54. Weiner SJ, Schwartz A, Sharma G, et al. Patient-centered decision making and health care outcomes: an observational study. Ann Intern Med. 2013;158:573-579.

55. Wright-Nunes JA, Osborn CY, Ikizler TA, Cavanaugh KL. Health numeracy: perspectives about using numbers in health management of African American patients receiving dialysis. Hemodial Int. 2015;19(2):287-295.

56. Reddy YN, Sundaram V, Abraham G, Nagarajan P, Reddy YN. Optimal management of hyperphosphatemia in end-stage renal disease: an Indian perspective. Int J Nephrol Renovasc Dis. 2014;7:391-399.

57. Ando S, Morimoto Y, Arai H. The effect of various boiling conditions on reduction of phosphorus and protein in meat. J Ren Nutr. 2015;25(6):504-509.

58. Burrowes JA, Ramen NJ. Removal of potassium from tuberous vegetables by leaching. J Ren Nutr. 2006;16(4):304-311.

59. Serfaty MA, Haworth D, Blandhard M, Buszewicz M, Murad S, King M. Clinical effectiveness of individual cognitive behavioral therapy for depressed older people in primary care: a randomized controlled study. Arch Gen Psychiatry. 2009;66(12):1332-1340.

60. Beto JA, Schury K, Nicholas M, Moravcik N, Baldovino B, Bansal VK. Use of talking control support therapy in chronic hemodialysis patient results in higher patient satisfaction survey response. Poster presented at: The National Kidney Foundation Spring Clinical Meetings; April; 2012; Washington, DC.

61. Heartland Kidney Network. Quality Improvement Activity Project Plan: Take 5 to Tune in. Summary Report, October 15, 2014. Kansas City, MO: Heartland Kidney Network; 2014:1-9.

62. Parker K, Nikam M, Jayanti A, Mitra S. Medication burden in CKD-5D: impact on dialysis modality and setting. Clin Kidney J. 2014;7(6): $557-661$.

63. Weinmann T, Thomas S, Brilmayer S, Henrich S, Radon R. Testing Skype as an interview method in epidemiological research: response and feasibility. Int J Public Health. 2012;57:959-961.

64. Fournet RM. Technology and applications: how can they help dietitians? Ren Nutr Forum. 2014;33(3):1-6.

65. Ryan KJ, Casas JM, Mash LE, et al. The effect of intensive nutrition interventions on weight gain after kidney transplantation: protocol of a randomised controlled trial. BMC Nephrol. 2014;15:148. 


\section{Supplementary Materials}

Basic Recipe:

1 jar (2.5 oz/75 g) pureed meat (turkey, chicken, beef) baby food;

$1 / 4$ cup $(2 \mathrm{oz} / 60 \mathrm{~mL}$ ) non-dairy creamer (rinse out baby food jar with liquid);

Pinch of dried herbs or 1 Tbsp $(5 \mathrm{~g})$ fresh chopped herbs;

Step 1: Use a microwave-safe beverage cup of 6-8 ounce (180-240 mL) capacity;

Step 2: Empty the jar of baby food into the beverage cup;

Step 3: Fill the empty jar with non-dairy creamer and shake to remove all of the remaining baby food. Empty into beverage cup;

Step 4: Add herbs;

Step 5: Mix well with a spoon;

Step 6: Cover cup with a paper towel and microwave for 45 seconds on high power. Stir. Check for temperature and increase cooking time as necessary for a hot soup.

You can substitute other liquids for the non-dairy creamer. Some chronic kidney disease patients bring their baby food jar to a restaurant and ask for hot water to mix at the table. Patients are encouraged to be creative, share "recipes", and work with their dietitian to understand nutrient changes of these recipe modifications. Some patients double the recipe, add "leftovers" (noodles, rice, cooked vegetables), and create a meal with $20 \mathrm{~g}$ of protein and low-sodium content. Patients are encouraged to take a phosphate binder as appropriate depending on the recipe.

Frozen peanut butter/jelly sandwich recipe:

Supplementary Video

\section{Publish your work in this journal}

The International Journal of Nephrology and Renovascular Disease is an international, peer-reviewed open-access journal focusing on the pathophysiology of the kidney and vascular supply. Epidemiology, screening, diagnosis, and treatment interventions are covered as well as basic science, biochemical and immunological studies. The journal welcomes

\section{Dovepress}

original research, clinical studies, reviews \& evaluations, expert opinion and commentary, case reports and extended reports. The manuscript management system is completely online and includes a very quick and fair peerreview system, which is all easy to use. Visit http://www.dovepress.com/ testimonials.php to read real quotes from published authors.

\footnotetext{
Submit your manuscript here: http://www.dovepress.com/international-journal-of-nephrology-and-renovascular-disease-journal
} 